\section{Подготовка к сертификации систем менеджмента качества технического сервиса}

\author{
А. А Шубин ${ }^{1}$, \\ А. П. Соколов \\ Петрозаводский государственный университет
}

\begin{abstract}
АННОТАЦИЯ
В статье рассмотрены проблемы создания и подготовки к сертификации систем менеджмента качества технического сервиса на предприятиях Республики Карелия с применением технологий ARIS.
\end{abstract}

Ключевые слова: сертификация, менеджмент качества, технический сервис, ARIS.

\section{SUMMARY}

This paper is connected with a quality management and certification of technical service in Karelia by using ARIS Toolset.

Keywords: certification, quality management, technical service, ARIS.

\section{ВВЕДЕНИЕ}

Для текущей экономической ситуации в Республике Карелия актуальной задачей становится сертификация систем менеджмента качества (СМК) для предприятий, занимающихся техническим сервисом и ремонтом автотранспортной техники. Если еще несколько лет назад СМК разрабатывались только на предприятиях-экспортерах, то теперь в Карелии есть примеры создания и сертификации СМК на предприятиях и в организациях, работающих на внутреннем рынке. Имеющиеся тенденции следует учитывать при подготовке специалистов для лесного комплекса Карелии.

\section{ПРЕДПОСЫЛКИ ВНЕДРЕНИЯ СМК НА ПРЕДПРИЯТИЯХ, ЗАНИМАЮЩИХСЯ ТЕХНИЧЕСКИМ СЕРВИСОМ АВТОТРАНСПОРТНОЙ ТЕХНИКИ}

Современная, сложная и динамичная рыночная среда требует от российских предприятий постоянного совершенствования своих систем управления. Одним из основных направлений создания эффективной системы управления предприятием является применение процессного подхода к организации и управлению деятельностью. Бизнес в сервисных компаниях можно отнести к категории консервативных. Целью здесь является достижение удовлетворения потребностей клиента при строго контролируемых затратах. Средством достижения поставленной цели - оптимизация и непрерывное улучшение бизнес-процессов. В отличие от промышленности тут нет больших возможностей для обновления ассортимента выпускаемой про-

\footnotetext{
${ }^{1}$ Авторы-соответственно доцент кафедры технологии металлов и ремонта, старший преподаватель кафедры тяговых машин

(C) А. А. Шубин, А. П. Соколов, 2003
}

дукции. Организация бизнес-процессов здесь является основным рычагом конкурентной борьбы.

Основой для создания современной системы менеджмента на предприятиях является процессная модель. Для создания процессных моделей в настоящее время применяется достаточно много инструментальных средств (BPwin, Erwin, S-Designor, EasyABC, CASE.Аналитик, Designer/2000, ABC FlowCharter, EasyCASE, Silverrun, PRO-IV, ARIS и др.). На лесоинженерном факультете ПетрГУ имеется лицензионная версия пакета ARIS Toolset и накоплен достаточный опыт использования его в учебных и научных целях. Тематика многих дипломных проектов специальности «Машины и оборудование лесного комплекса» связана с вопросами организации и менеджмента технического сервиса на автотранспортных предприятиях Республики Карелия. В ходе дипломного проектирования студенты специализации «Сервис и техническая эксплуатация машин и оборудования лесного комплекса» разрабатывают модели отдельных производственных процессов, предлагают решения по их модернизации. Имеются данные по большинству достаточно крупных предприятий Петрозаводска, которые занимаются данным видом бизнеса. Таким образом, на лесоинженерном факультете имеются предпосылки для создания типового алгоритма решения, которое могло бы служить основой для модернизации управления предприятиями, занимающимися техническим сервисом и ремонтом автотранспортной техники.

\section{РАЗРАБОТКА И ПРИМЕНЕНИЕ МОДЕЛЕЙ ПРОИЗВОДСТВЕННЫХ ПРОЦЕССОВ ДЛЯ СЕРТИФИКАЦИИ СМК НА СООТВЕТСТВИЕ СТАНДАРТАМ ИСО 9000:2000}

Стандарт ИСО 9001:2000 ориентирован на процессный подход к менеджменту качества. Поэтому основой для разработки СМК может служить процессная модель, разработанная в среде ARIS Toolset.

Процессы моделируются «сверху — вниз» с помощью диаграмм цепочек добавленной стоимости. Цепочки добавленной стоимости разбиваются на отдельные процессы, которые распределяются по многочисленным уровням. Пример диаграммы показан на рис. 1 .

Затем процессы представляются как еЕРС-диаграммы. ARIS Toolset позволяет к каждой функции eEPCмодели добавить текстовое описание, а также показать, какие документы, оборудование, механизмы, вспомогательные средства, информационные ресурсы связаны с данной диаграммой. Если далее процесс нуждается в количественном анализе, то можно ввести показатели времени и издержек, а также определить стоимость и трудоемкость бизнес-процесса, трудозатраты участников и загрузку оборудования. Пример диаграммы показан на рис. 3 .

Основным документом системы качества является «Руководство по качеству», которое составляется в соответствии со стандартом ИСО 10013:1995. Описания процессов для «Руководства по качеству» создаются непосредственно из диаграмм цепочек добавленной стоимости, разработанных в ARIS Toolset. Методологические и рабочие инструкции создаются на базе 


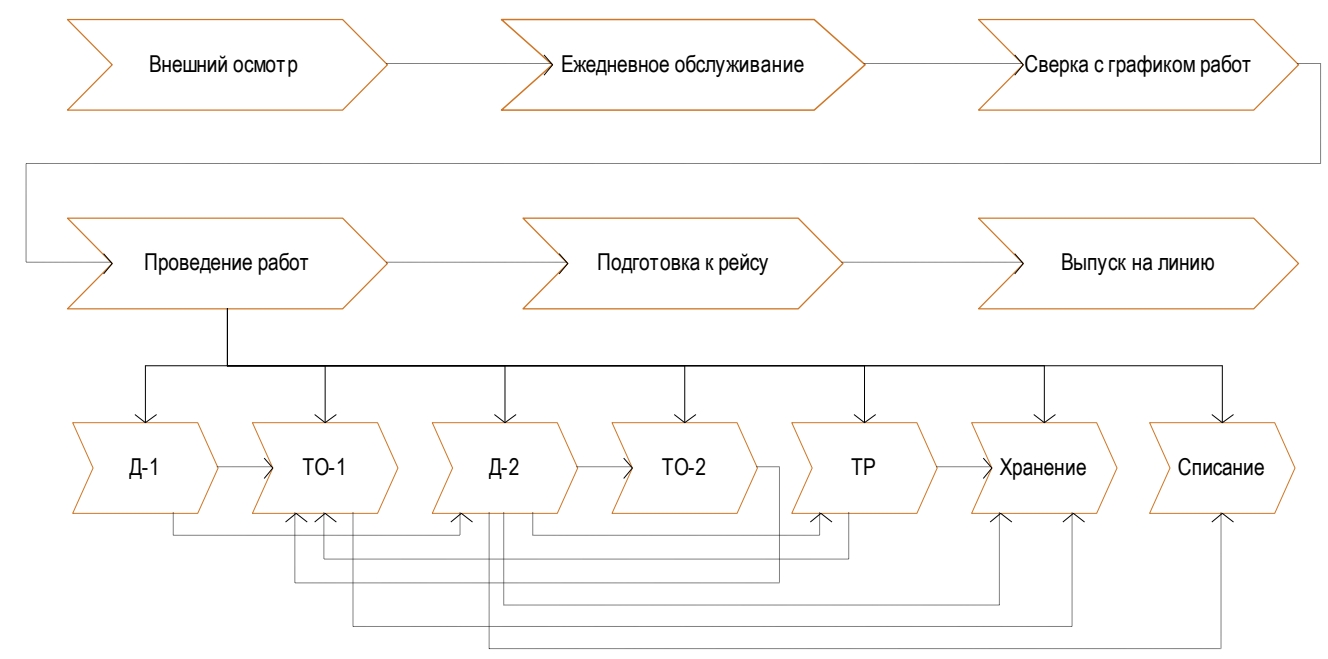

Рис. 1. Пример диаграммы цепочек добавленной стоимости:

Д-1 - диагностика-1; Д-2 - диагностика-2; ТО-1 - техническое обслуживание-1; ТО-2 - техническое обслуживание- 2 ; ТР - текущий ремонт

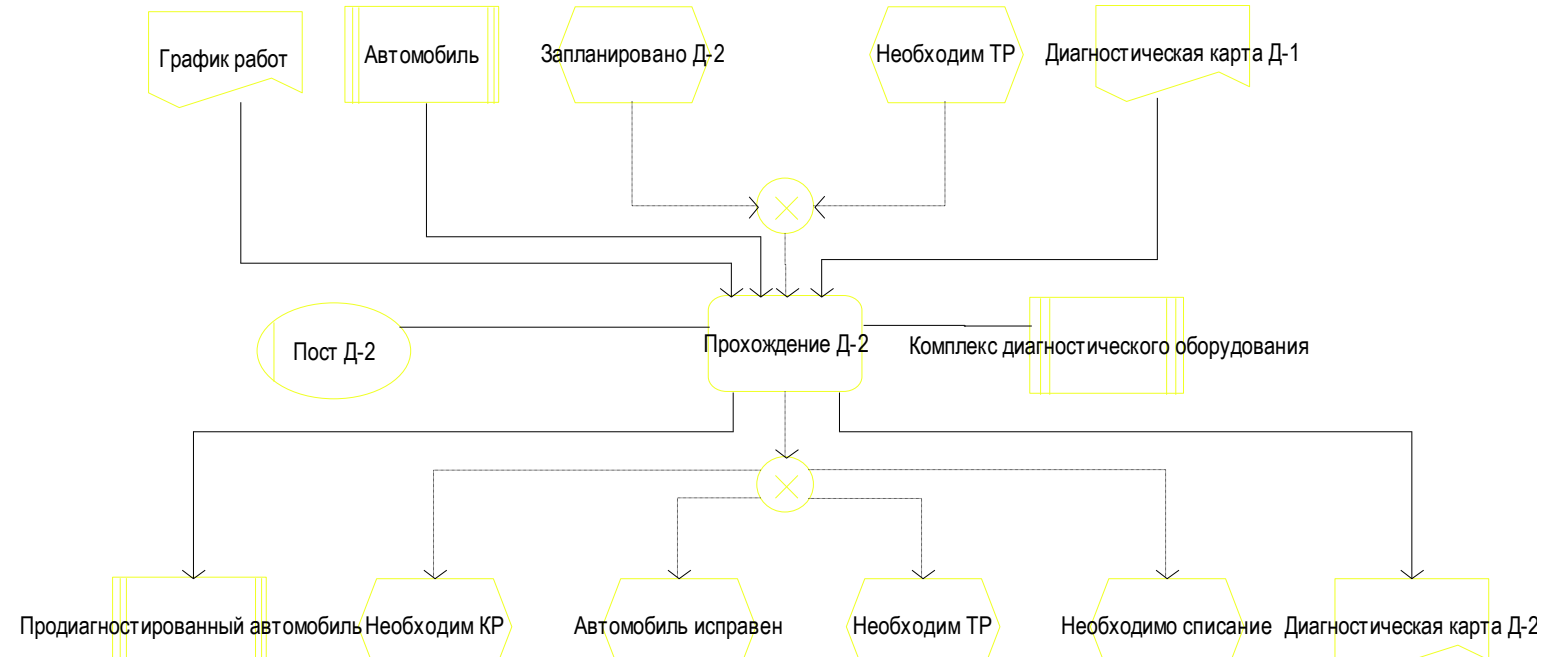

Рис. 2. Пример FAD-модели

eEPC-диаграмм и FAD-моделей. Пример FAD-модели показан на рис. 2.

В настоящее время становятся очевидными преимущества модели в электронном виде над бумажной версией СМК, где документы и перекрестные ссылки поддерживаются вручную. Если раньше модель в электронном виде была желательным дополнением к документации на бумаге, то теперь модель в электронном виде становится основной.

Документация СМК имеет несколько уровней. Наиболее многочисленными являются документированные процедуры (предназначенные для инженеров и руководителей среднего звена) и рабочие инструкции (предназначенные для исполнителей). При наличии моделей процессов в электронном виде с необходимыми комментариями сетевые возможности ARIS и других подобных систем позволяют обойтись без составления подробных рабочих инструкций. Вместо этого исполнителям гарантируется доступ к нужным частям базы данных.

B семействе ARIS существует специальное программное решение, которое поддерживает процессную модель, помогает предприятиям в процедуре внедрения стандартов ИСО 9000 и получения сертификата, а также адаптирует уже реализованные процессы к новой редакции стандарта ИСО 9000:2000 - Проводник Менеджмента Качества (Quality Management Scout). Применение этого программного средства позволяет 


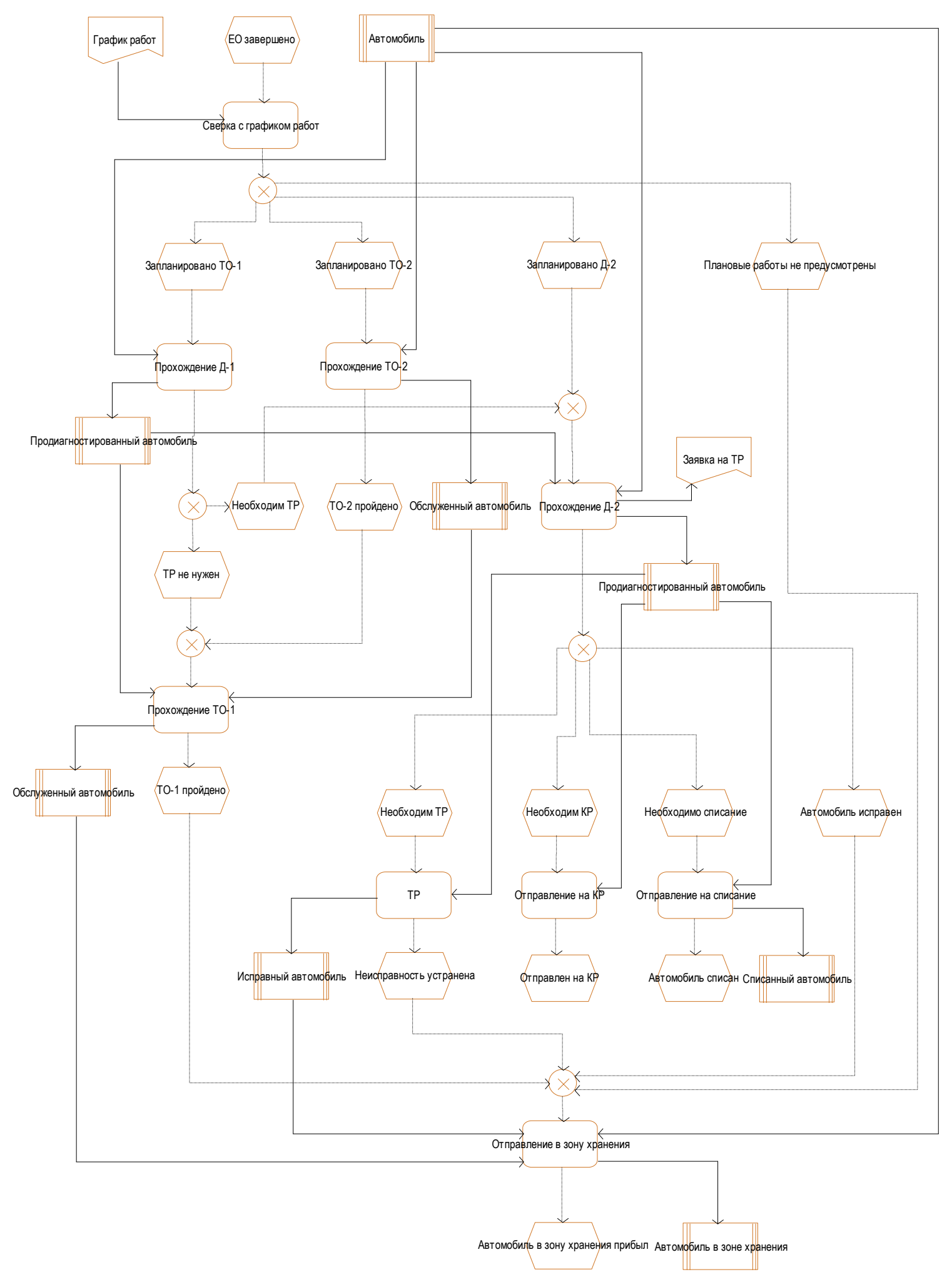

Рис. 3. Пример еЕРС-диаграммы (см. обозначения рис. 1) 
на основе процессной модели быстро разработать руководство по качеству.

\section{ЗАКЛЮЧЕНИЕ}

Создание полной процессной модели типичного предприятия по техническому сервису и ремонту автотранспортной техники будет служить основой для дальнейшей научной и учебной работы. В качестве актуальных задач, решаемых с помощью такой модели, можно выделить следующие:

- проведение функционально-стоимостного анализа (поэлементного анализа затрат);
- анализ и оптимизацию бизнес-процессов;

- разработку элементов системы менеджмента качества.

\section{СПИСОК ЛИТЕРАТУРЫ}

1. ГОСТ Р ИСО 9004-2001.

2. Шеер А.-В. Бизнес-процессы. Основные понятия. Теория. Методы: Пер с англ. 2-е изд., перераб. и доп. М.: Весть - МетаТехнология, 1999. $156 \mathrm{c}$. 